\title{
Skeletal myogenesis on highly orientated microfibrous polyesterurethane scaffolds
}

\author{
S.A. Riboldi, ${ }^{1}$ N. Sadr ${ }_{1}^{1}$ L. Pigini, ${ }^{1}$ P. Neuenschwander, ${ }^{2}$ M. Simonet, ${ }^{2}$ P. Mognol, ${ }^{3}$ M. Sampaolesi, ${ }^{3}$ \\ G. Cossu, ${ }^{3}$ S. Mantero ${ }^{1}$ \\ ${ }^{1}$ Department of Bioengineering, Politecnico di Milano, 20133 Milano, Italy \\ ${ }^{2}$ Department of Materials-Polymer Technology, ETH Zurich, 8092 Zürich, Switzerland \\ ${ }^{3}$ SCRI Stem Cell Research Institute, San Raffaele Scientific Institute, 20132 Milano, Italy
}

Received 14 February 2006; revised 27 February 2007; accepted 15 May 2007

Published online 8 August 2007 in Wiley InterScience (www.interscience.wiley.com). DOI: 10.1002/jbm.a.31534

\begin{abstract}
Skeletal myogenesis is a complex process, which is known to be intimately depending on an optimal outside-in substrate-cell signaling. Current attempts to reproduce skeletal muscle tissue in vitro using traditional scaffolds mainly suffer from poor directionality of the myofibers, resulting in an ineffective vectorial power generation. In this study, we aimed at investigating skeletal myogenesis on novel biodegradable microfibrous scaffolds made of DegraPol ${ }^{\mathbb{R}}$, a block polyesterurethane previously demonstrated to be suitable for this application. DegraPol ${ }^{\mathbb{R}}$ was processed by electrospinning in the form of highly orientated (" $\mathrm{O}$ ") and nonorientated ("N/ $\left.\mathrm{O}^{\prime \prime}\right)$ microfibrous meshes and by solvent-casting in the form of nonporous films (" $\left.\mathrm{F}^{\prime}\right)$. The effect of the fiber orientation at the
\end{abstract}

scaffold surface was evaluated by investigating C2C12 and L6 proliferation (via SEM analysis and alamarBlue ${ }^{\mathrm{TM}}$ test) and differentiation (via RT-PCR analysis and MHC immunostaining). We demonstrated that highly orientated elastomeric microfibrous DegraPol ${ }^{\mathbb{R}}$ scaffolds enable skeletal myogenesis in vitro by aiding in (a) myoblast adhesion, (b) myotube alignment, and (c) noncoplanar arrangement of cells, by providing the necessary directional cues along with architectural and mechanical support. (C) 2007 Wiley Periodicals, Inc. J Biomed Mater Res 84A: 1094-1101, 2008

Key words: myogenesis; skeletal muscle; tissue engineering; electrospinning; fiber orientation

\section{INTRODUCTION}

The process of myogenesis during in vivo development results in a well-organized, hierarchically structured skeletal muscle tissue, where fibers are arranged in highly dense unidirectional assemblages, allowing the generation of a large vectorial muscular power. $^{1-3}$

The emerging field of skeletal muscle tissue engineering, primarily aiming at reproducing myogenesis in vitro, mainly suffers from the difficulty of driving cell proliferation and, above all, differentiation and fusion into contractile myofibers packed in three-dimensional constructs. Two-dimensional myotube cultures with a high degree of myogenic differentiation and sarcomeric maturity can be easily obtained on tissue culture polystyrene; nonetheless they are difficult to maintain, as more mature

Correspondence to: S.A. Riboldi, Institute for Surgical Research and Hospital Management, University Hospital Basel, ZLF, Hebelstrasse 20, 4031 Basel, Switzerland; e-mail: stefania.riboldi@polimi.it

(C) 2007 Wiley Periodicals, Inc. myotubes are contractile and readily detach from the tissue culture substratum. ${ }^{4}$ In this context, coherently with the so-called "contact guidance theory," capability of skeletal myoblasts to differentiate and survive on synthetic scaffolds was demonstrated to broadly correlate with chemical, topographical, and mechanical properties of the substrate itself. ${ }^{4,7} 8$ Hence, promising results are shown by studies employing microfibrous scaffolds, which succeeded in driving myofiber development and orientation along the preferential direction of the scaffold fibers. ${ }^{5,9,10}$ In agreement with these works, we previously demonstrated that $\operatorname{DegraPol}^{\mathbb{R}}$, a block polyesterurethane, processed in the form of microfibrous meshes, provides a substrate for myoblast cell lines (C2C12 and L6) and primary human satellite cell adhesion and proliferation. ${ }^{11}$

The study here attempted to deepen the investigation of skeletal myoblast behavior on DegraPol ${ }^{\circledR}$ membranes, in terms of adhesion, proliferation, and differentiation into multinucleated myotubes expressing myogenic markers. In particular, the final goal of the project being to assess an optimal scaffold design for use in skeletal muscle tissue engineering, we investigated myoblast differentiation potential on $\operatorname{DegraPol}^{\mathbb{R}}$ 
scaffolds that, though identical in chemical composition, differed in surface morphology with reference to the orientation of fibers on the membrane surface. To process the block copolymer in such different shapes, we made use of electrospinning, a highly versatile, promising processing technique, which allows tailoring of the scaffold properties to the specific application by tuning processing parameters. $^{12,13} \mathrm{~A}$ quantitative assessment of cell metabolic activity was performed seeding and culturing $\mathrm{C} 2 \mathrm{C} 12$ on highly orientated $\left(" \mathrm{O}\right.$ ") and nonorientated $\left(" \mathrm{~N} / \mathrm{O}^{\prime \prime}\right)$ DegraPol ${ }^{\mathbb{R}}$ membranes and on nonporous DegraPol ${ }^{\circledR}$ films $\left(" \mathrm{~F}^{\prime \prime}\right)$. Subsequently, the effect of the scaffold fiber orientation on myotube arrangement was qualitatively investigated by means of immunostaining of MHC (Myosin Heavy Chain), which is recognized as a marker of terminal differentiation.

The working hypothesis was that highly orientated elastomeric microfibrous scaffolds would allow skeletal myogenesis in vitro by (a) improving cell adhesion and proliferation, (b) favoring myotube alignment into parallel arrays, and (c) allowing for development of noncoplanar myofibers.

\section{MATERIALS AND METHODS}

\section{Polymer synthesis and purification}

For the synthesis of the block copolymer, equal amounts of $\operatorname{poly}\{(3-(\mathrm{R})$-hydroxybutyrate)-co-( $\varepsilon$-caprolactone $)\}$-diol and poly( $\varepsilon$-caprolactone)-diol were dissolved in 1.4-dioxane and dried by refluxing the solvent over molecular sieve (pore size $0.4 \mathrm{~nm}$ ) situated in a Soxhlet apparatus mounted onto the reaction vessel, until the water content was below $20 \mathrm{ppm}$. The reaction mixture was cooled to $83^{\circ} \mathrm{C}$ before the stoichiometric amount of diisocyanate (TMDI) was added. After about 3 days of reaction, dibutyltin dilaurate (20 ppm) was added to reach molecular weights between 60,000 and 110,000 . The polymer was precipitated in $\mathrm{CO}_{2}$-cooled methanol and subsequently purified via dissolution in chloroform and filtration over a silicagel 60 column. A second precipitation in $\mathrm{CO}_{2}$-cooled methanol ended the process.

\section{Scaffold production and characterization}

Scaffolds with different morphologies were fabricated by processing a $25 \% \mathrm{w} / \mathrm{w}$ polymer-chloroform solution in three different ways. Microfibrous membranes were manufactured by electrospinning, applying high voltage $(18 \mathrm{kV})$ between a needle and a grounded rotating cylindrical collector; highly orientated ("O $\left.\mathrm{O}^{\prime}\right)$ and nonorientated ("N/O") meshes, only differing in the percentage of parallely orientated fibers of the surface layer (about $10 \mu \mathrm{m}$ thick), were obtained ending up the electrospinning sessions with cycles at different speeds (linear rates of the rotating collector $7.6 \mathrm{~m} / \mathrm{s}$ and $0.4 \mathrm{~m} / \mathrm{s}$ at the edge, respectively). As a control, uniform thin films of the copolymer ("F") were manufactured by solvent-casting. After drying the membranes in high vacuum at room temperature, round scaffolds were obtained by means of a 9-mm-diameter punch, washed in absolute ethanol $\left(30 \mathrm{~min}\right.$, at $\left.-20^{\circ} \mathrm{C}\right)$ and hexane (30 $\mathrm{min}$, at room temperature) and subsequently sterilized with ethylene oxide at $37^{\circ} \mathrm{C}$.

For characterization, scaffold thickness was measured using a digital micrometer (Mitutoyo America Corporation), while membrane morphology was investigated by means of SEM (Scanning Electron Microscopy): samples were sputter-coated with gold (Edwards S150B, 1 min, $20 \mathrm{~mA}, 10^{-1}$ Torr) before examination under a Jeol JSM $5500 \mathrm{LV}$ microscope at an accelerating voltage of $10 \mathrm{kV}$.

\section{Cell culture}

C2C12 (murine myoblast cell line, ECACC) was used between passage 12 and passage 17, while L6 (rat myoblast cell line, ATCC) were used at passage 20. Cells were plated in $75 \mathrm{~cm}^{2}$ tissue-culture flasks and cultured in DMEM (Dulbecco's modified Eagle's medium, Sigma-Aldrich, St. Louis, MO) supplemented with 10\% FBS (Fetal Bovine Serum, Sigma-Aldrich, St. Louis, MO) adjusted to contain 1\% L-glutamine (Sigma-Aldrich, St. Louis, MO) and 1\% penicillinstreptomycin (Sigma-Aldrich, St. Louis, MO). Flasks were incubated at $37^{\circ} \mathrm{C}$ in a humidified $5 \% \mathrm{CO}_{2}$ atmosphere. Cells were subcultured at semiconfluence.

\section{Cell proliferation on scaffolds with different surface morphologies}

Since myoblast growth to subconfluence is known to be a prerequisite for cell fusion and differentiation, ${ }^{7,14}$ cell proliferation on scaffolds with different morphologies was investigated seeding and culturing $\mathrm{C} 2 \mathrm{C} 12$ (seeding density $2.8 \times 10^{4}$ cells $/ \mathrm{cm}^{2}$ ) for 7 days on "O," "N/O," and " $\mathrm{F}^{\prime}$ DegraPol $^{\mathbb{R}}(n=6)$, using TCPS (Tissue Culture PolyStyrene) as a control $(n=6)$. Cell metabolic activity was evaluated via alamarBlue ${ }^{\mathrm{TM}}$ test (BioSource International, Camarillo, CA) at days 1, 2, 3, 4, and 7 after seeding. Following $4 \mathrm{~h}$ of cell incubation in a $10 \%$ alamarBlue $\mathrm{TM}_{-}^{\mathrm{TM}}$ medium solution, absorbance values were measured by means of a Tecan GENios microplate reader (Tecan Group, Maennedorf, Switzerland) at a wavelength of $570 \mathrm{~nm}$ (reference wavelength $630 \mathrm{~nm}$ ).

Cell morphology on the different scaffolds was investigated by SEM analysis at days 1 and 7 after seeding: briefly, following fixation in $1.5 \%$ glutaraldehyde in sodium cacodylate $0.1 \mathrm{M}$, samples were rinsed, dehydrated by graded ethanol changes (from 20 to $100 \%$ ethanol in deionizer water), air dried overnight, and sputter-coated with gold (Edwards S150B, $1 \mathrm{~min}, 20 \mathrm{~mA}, 10^{-1}$ Torr) before examination under a Jeol JSM 5500 LV microscope at an accelerating voltage of $7.5 \mathrm{kV}$.

\section{Expression of myogenic markers}

The expression of typical muscle markers was evaluated via RNA extraction and RT-PCR analysis using both 

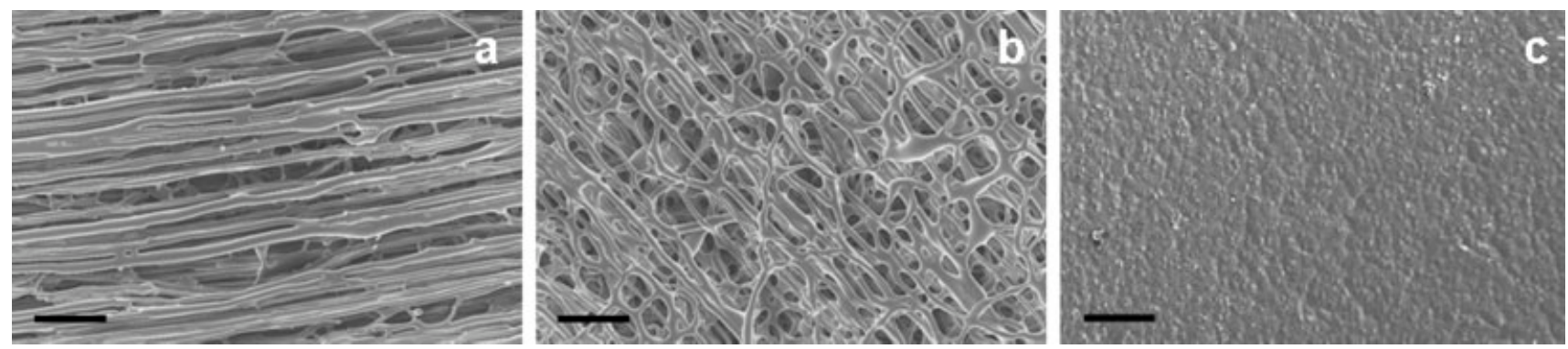

Figure 1. SEM micrographs of DegraPol ${ }^{\mathbb{R}}$ scaffolds with different topographies. Highly orientated [“O”, Fig. 1(a)] and nonorientated ["N/O", Fig. 1(b)] DegraPol ${ }^{\circledR}$ meshes were obtained by electrospinning with high speed $(7.6 \mathrm{~m} / \mathrm{s})$ and low speed $(0.4 \mathrm{~m} / \mathrm{s})$ spinning sessions, respectively. Nonporous DegraPol ${ }^{\mathbb{R}}$ films [Fig. 1(c)] were obtained by solvent-casting from the same polymer-chloroform solution. Scale bars $=100 \mu \mathrm{m}$.

$\mathrm{C} 2 \mathrm{C} 12$ and $\mathrm{L} 6$ on Matrigel $^{\mathbb{R}}$-coated “O” DegraPol $^{\mathbb{R}}$ meshes. The use of Matrigel ${ }^{\circledR}$ was introduced in this experiment, in an attempt to increase the fraction of seeded cells adhering to " $\mathrm{O}$ " DegraPol ${ }^{\mathbb{R}}$ and thus optimizing cell yield for RT-PCR, since in one of our previous works, ${ }^{11}$ we experienced better adhesive properties of Matrigel ${ }^{\mathbb{R}}$-coated DegraPol ${ }^{\mathbb{R}}$ membranes when compared to native DegraPol ${ }^{\mathbb{R}}$. Briefly, cells were seeded on Matrigel ${ }^{\mathbb{R}}$-coated (Becton Dickinson and Company, Franklin Lakes, NJ) “ $\mathrm{O}^{\prime}$ DegraPol ${ }^{\mathbb{R}}$ scaffolds at densities of 4.2 $\times 10^{4}$ cells $/ \mathrm{cm}^{2}$ and $3.0 \times 10^{4}$ cells $/ \mathrm{cm}^{2}$, respectively; after 7 days of culture in growth medium, cells were further grown for 7 days in differentiation medium (DMEM supplemented with $2 \%$ horse serum). TCPS was used as a control. At day 14, total RNA was isolated using the RNeasy Mini Kit and subsequently purified via digestion of DNA by means of RNase-Free DNase Set (QIAGEN, Hilden, Germany). RT-PCR protocol was carried out with Thermo-Script ${ }^{\mathrm{TM}}$ RT-PCR System (Invitrogen, Carlsbad, CA) using Platinum ${ }^{\circledR}$ Taq DNA Polymerase. The presence of cDNA corresponding to MHC (Myosin Heavy Chain) and myogenin was evaluated via agarose gel electrophoresis and ethidium bromide staining.

\section{Cell fusion and differentiation}

With the aim to verify the influence of the fiber orientation at the scaffold surface on myotube development and arrangement, $\mathrm{C} 2 \mathrm{C} 12$ were seeded $\left(2.8 \times 10^{4}\right.$ cells $\left./ \mathrm{cm}^{2}\right)$ on “O," "N/O," and "F" DegraPol ${ }^{\circledR}$ and cultured for 14 days in $10 \%$ FBS-supplemented medium. Medium was exchanged every second day and TCPS was used as a control. At days 5, 6, 7, 8, 9, 12, 13, and 14 after seeding, cells were fixed in $2 \%$ paraformaldehyde in PBS and subsequently stained for MHC and nuclei as follows: samples were rinsed, permeabilized for $30 \mathrm{~min}$ at room temperature by addition of a buffer containing $0.1 \%$ Triton X-100 (Sigma-Aldrich, St. Louis, MO) and 1\% w/w BSA (Bovine Serum Albumin, Sigma-Aldrich, St. Louis, MO) and blocked with PBS containing 10\% donkey serum for 30 min at room temperature. Following incubation for $1 \mathrm{~h}$ with a monoclonal mouse anti-MHC primary antibody (MF20, 1:2 in PBS), samples were rinsed twice using the permeabilizing solution and then incubated for $1 \mathrm{~h}$ in a solution containing donkey-antimouse fluorescein isothiocya- nate (FITC) conjugated secondary antibody (Sigma-Aldrich, St. Louis, MO, 1:1000 in PBS) and 0.05\% Hoechst as a nuclear marker (Sigma-Aldrich, St. Louis, MO). The immunostained samples were subsequently mounted on glass slides and viewed by means of a Nikon E600 fluorescence microscope, equipped with Nikon ACT-1 software, and using a Zeiss LSM 510 laser scanning confocal microscope.

\section{Statistical analysis}

Absorbance values are expressed as means \pm standard deviations. Comparison of cell proliferation on different substrates was performed by means of single-factor analysis of variance (ANOVA) and Bonferroni post-hoc test. A value of $p<0.01$ was accepted as statistically significant.

\section{RESULTS}

\section{Scaffold production and characterization}

SEM micrographs of DegraPol ${ }^{\circledR}$ scaffolds processed in different ways are shown in Figure 1: Figures 1(a) and $1(b)$ represent microfibrous orientated $(" \mathrm{O}$ ") and nonorientated ("N/O") electrospun membranes, respectively, while Figure 1(c) describes the morphology of nonporous cast DegraPol ${ }^{\circledR}$ films ("F"). Regardless of the processing method, a good degree of homogeneity of the scaffold surface is detectable. Though a slight preferential orientation of fibers is observable both in " $\mathrm{O}$ " and "N/O" membranes due to the rotational direction of the cylindrical collector during electrospinning processing, a clear difference between " $\mathrm{O}$ " and " $\mathrm{N} / \mathrm{O}^{\prime}$ " scaffolds is visible with reference to the percentage of fibers directed in the same direction. As far as the thickness is concerned, spun membranes and films are 150 and $90 \mu \mathrm{m}$ thick, respectively.

\section{Cell proliferation on scaffolds with different surface morphologies}

Aiming at quantifying cell metabolic activity on scaffolds that, although chemically identical, differed 


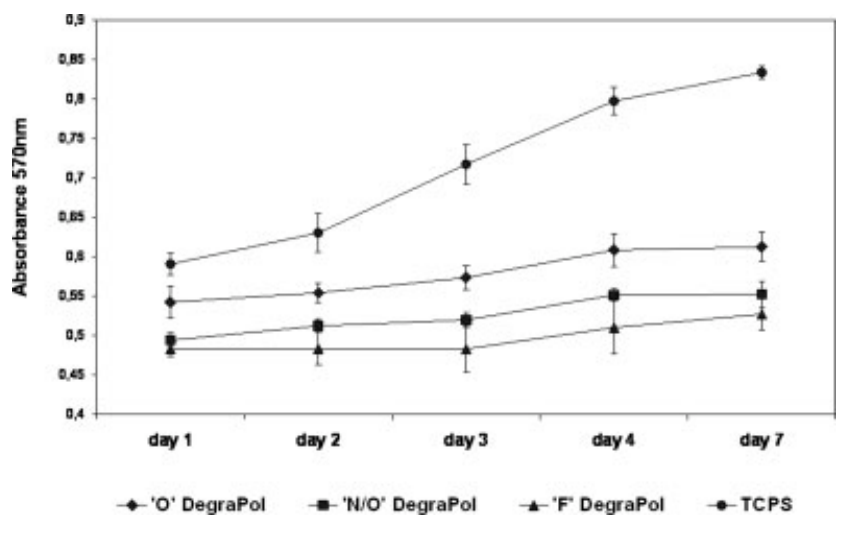

Figure 2. $\mathrm{C} 2 \mathrm{C} 12$ proliferation on DegraPol ${ }^{\circledR}$ scaffolds. Cell metabolic activity was evaluated at different time points via alamarBlue ${ }^{\mathrm{TM}}$ test, by measuring absorbance values at $570 \mathrm{~nm}$ (reference wavelength $630 \mathrm{~nm}$ ). "O," "N/ $\mathrm{O}$," and " $\mathrm{F}^{\prime} \mathrm{DegraPol}^{\mathrm{R}}$ scaffolds were compared to tissue culture polystyrene (TCPS), used as a control $(n=6)$. ANOVA analysis and Bonferroni post-hoc test showed that, irrespective of the time point, $\mathrm{C} 2 \mathrm{C} 12$ had significantly higher metabolic activity $(p<0.01)$ on "O" DegraPol ${ }^{\circledR}$ meshes with respect to "N/O" and " $\mathrm{F}$ " scaffolds. Nonetheless, the higher absorbance value displayed by cells on " $\mathrm{O}$ " DegraPol $^{\mathbb{R}}$ at time point DAY 1 induces to conclude that the main effect of the fiber orientation at the scaffold surface is expressed in increased cell adhesion in the first $24 \mathrm{~h}$ after seeding.

in respect to the surface morphology, cell proliferation was evaluated via alamarBlue ${ }^{\mathrm{TM}}$ test culturing $\mathrm{C} 2 \mathrm{C} 12$ on DegraPol ${ }^{\circledR}$ for 7 days in growth medium. Absorbance values at $560 \mathrm{~nm}$ were measured at days $1,2,3,4$, and 7 after seeding using TCPS as a control. The results of the colorimetric assay are shown in Figure 2. Confirming a clear tendency of cells to proliferate on DegraPol ${ }^{\mathbb{R}}$, absorbance values were shown to increase over time with reference to all the scaffolds under investigation. Regardless of the time point, cells grown on "O" DegraPol ${ }^{\circledR}$ showed metabolic activity closer to the control and significantly higher $(p$ $<0.01$ ) if compared to cells cultured on "N/O" and "F" (giving, on the contrary, comparable values). De- spite of this, cell proliferation rate was shown to be similar among different DegraPol ${ }^{\circledR}$ scaffolds.

The morphology of cells proliferating on microfibrous " $\mathrm{O}$ " DegraPol $^{\circledR}$ scaffolds, investigated by means of SEM analysis, is shown in Figure 3. Micrographs in Figures $3(a, b)$ represent cells cultured in 10\% FBS supplemented medium for 1 and 7 days, respectively, showing a clear tendency of myoblasts to spread along the scaffold fibers by developing filopodia. Once attached to the fiber surface, C2C12 myoblasts spread out and multiplied, forming layers of cells aligning parallel to the fiber axis. Figure 3(c) highlights the capability of cells to penetrate the scaffold surface porosity, proliferating between "O" DegraPol $^{\circledR}$ fibers.

\section{Expression of myogenic markers}

With the aim to qualitatively and preliminarily investigate myoblast capability to differentiate on DegraPol $^{\circledR}$ scaffolds, the expression of a family of typical myogenic markers was evaluated via RT-PCR on $\mathrm{C} 2 \mathrm{C} 12$ and $\mathrm{L} 6$ cultured on " $\mathrm{O}$ " electrospun DegraPol $^{\circledR}$ meshes. The result of electrophoresis analysis performed on cDNA is shown in Figure 4, where TCPS represents the reference culture surface, while CTR + and CTR - indicate standard cDNA and water, respectively. After 14 days of culture on DegraPol $^{\circledR}(\mathrm{DP})$, both C2C12 and L6 exhibited levels of myogenin expression comparable to TCPS control. Both cell types were also shown to express MHC.

\section{Cell fusion and differentiation}

The capability of cells to fuse and differentiate into multinucleated myotubes on DegraPol ${ }^{\circledR}$ was further investigated by means of nuclei staining and immunofluorescence analysis of MHC. Figure 5 shows cell nuclei following 14 days of cell culture on " $\mathrm{O}$ " Degra$\mathrm{Pol}^{\circledR}$ in $10 \%$ FBS supplemented medium. Since cell
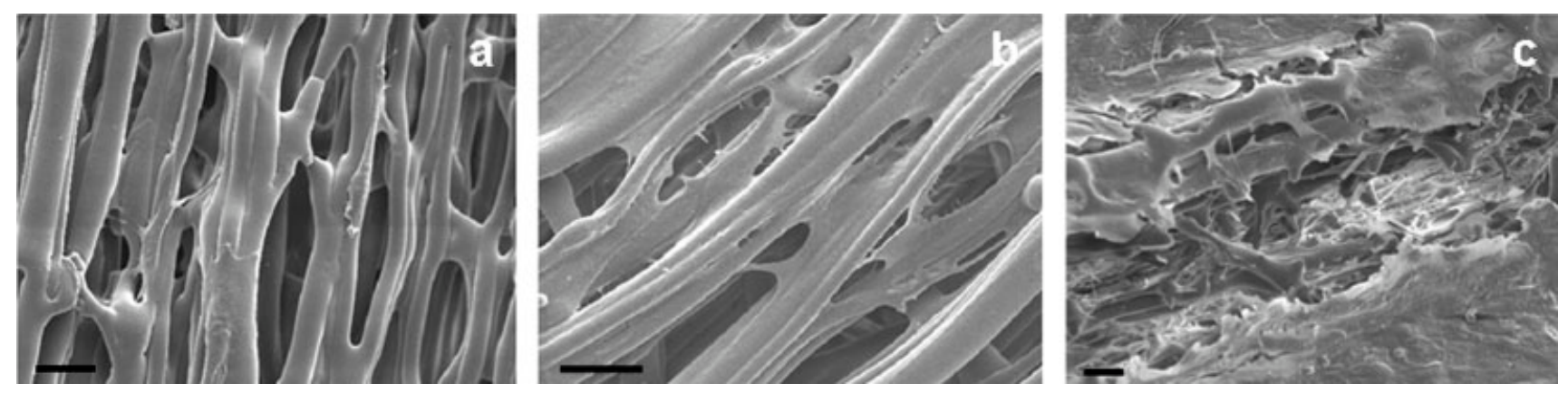

Figure 3. SEM micrographs of $\mathrm{C} 2 \mathrm{C} 12$ cultured on “O” DegraPol ${ }^{\circledR}$ scaffolds. Twenty-four hours after seeding, cells showed to adhere and spread on the scaffold fibers [Fig. 3(a)]. After 7 days of culture, C2C12 cultured in $10 \%$ FBS supplemented medium formed layers of cells aligning parallel to the fiber axis [Fig. 3(b)]. Figure 3(c) highlights the capability of $\mathrm{C} 2 \mathrm{C} 12$ to penetrate the scaffold surface porosity, spreading between DegraPol ${ }^{\mathbb{R}}$ fibers. Scale bars $=20 \mu \mathrm{m}$. 


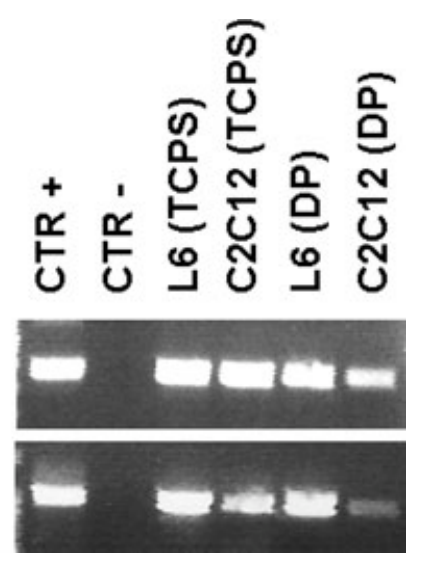

Figure 4. Expression of skeletal muscle markers on " $\mathrm{O}$ " DegraPol ${ }^{\mathbb{R}}$ meshes. RT-PCR analysis was carried out after culturing $\mathrm{C} 2 \mathrm{C} 12$ and L6 on "O" DegraPol ${ }^{\mathbb{R}}$ membranes for 14 days. Agarose gel electrophoresis shows that both cell types exhibited levels of myogenin expression comparable to TCPS control. C2C12 and L6 also expressed MHC, the reason for the different intensities being still unclear. CTR+ and CTR - represent standard DNA and water, respectively.

nuclei visibly lie on different focal plans, a noncoplanar arrangement of cells can be inferred; moreover, the evident tendency of cell nuclei to line up along the direction of the scaffold fibers strongly suggests the presence of multinucleated myotubes running parallel to the scaffold fibrous structure. Confirming this hypothesis, Figure 6 represents myosin-expressing myotubes (MHC marked in green, cell nuclei in blue), cultured for 14 days on "O," "N/O," and " $\mathrm{F}$ " DegraPol $^{\mathbb{R}}$ scaffolds [phase contrast micrographs shown in Figs. 6(c), 6(f), and 6(i), respectively]. In accordance with the highly directional structure of the underlying scaffold mesh, a high degree of orientation of myotubes is observable in the case of " $\mathrm{O}$ " DegraPol $^{\mathbb{R}}$ [Fig. 6(a,b)]. Myotubes grown on the "N/ $\mathrm{O}^{\prime \prime}$ scaffold, on the contrary, appear more randomly distributed [Fig. 6(d,e)]; on the nonporous " $F$ " Degra$\mathrm{Pol}^{\mathbb{R}}$, similar to what happened on TCPS, myotubes are shown to orient in small colonies [Fig. 6(g,h)], without being able to develop either an overall net orientation or a three-dimensional structure. The confocal analysis carried out on immunostained samples enabled to verify the sporadic presence of multinucleated myosin-expressing myotubes also beyond the scaffold surface. As an example, Figure 7 shows myotubes lying about $70 \mu \mathrm{m}$ below the scaffold surface in the case of " $\mathrm{O}$ " DegraPol ${ }^{\mathbb{R}}$; structures more than $200 \mu \mathrm{m}$ in length are detectable.

\section{DISCUSSION}

Skeletal myogenesis in vitro, key issue toward the development of functional skeletal muscle engineered tissue, is a complex, multistep process ${ }^{15}$ that has been extensively studied in the last 20 years. Beside contingent on cell-cell contact formation, myoblast differentiation into functional multinucleated myotubes was demonstrated to be intimately depending on an optimal outside-in substrate-cell signaling, ${ }^{7}$ thus revealing a primary role of the scaffold chemical, mechanical, and topographical properties in determining the functionality of the resulting engineered construct. To originate forceful and functional muscle tissue, skeletal muscle cells require sufficient cell density along with the appropriate cues to guide them in highly directional architectures. ${ }^{10}$

The vast majority of in vitro skeletal muscle basic studies were limited so far to solid surfaces consisting of tissue culture plastics or scaffolds made of traditional degradable polyesters (PLLA, PGA, and copolymers). Together the results of these works show that skeletal myogenesis is achievable in vitro; nonetheless, the attempts of obtaining fully differentiated functional muscle fibers in vitro still suffer from several issues. Among these, the most significant is probably the lack of long-range alignment of myotubes, which usually grow in mere short-range parallelism with neighboring cells, branching and overlaying, and thus preventing the development of large vectorial contraction forces. This issue, together with the difficulty of maintaining differentiated myocytes for sufficient lengths of time, could be easily solved by means of an attentive scaffold design, aimed at driving and sustaining tissue development.

In this context, in accordance with encouraging studies showing promising applications of microfibrous scaffolds in the field of skeletal muscle tissue engineering, $5,9,10$ in a previous work we demonstrated the potentialities of DegraPol ${ }^{\circledR}$, a degradable block polyesterurethane processed by electrospinning in the form microfibrous meshes, in terms of mechanical properties, degradation rate, and myoblast adhesion and proliferation. ${ }^{11}$

Based on the findings that cell-cell contacts are key elements toward the development of multinucleated muscle fibers ${ }^{7,14}$ and that scaffold topography can deeply influence cell response in terms of cell adhesion and proliferation, ${ }^{5,6,16}$ this study attempted at verifying whether highly orientated ("O') electrospun Degra$\mathrm{Pol}^{\mathrm{R}}$ scaffolds could present an advantage over nonorientated ("N/O") electrospun membranes and cast nonporous films (" $\mathrm{F}$ ") in terms of favoring myoblast adhesion and proliferation and, above all, of driving cell differentiation in a preferential direction. A brief discussion of our findings is given in the following.

\section{Cell adhesion and proliferation}

Since skeletal muscle cell differentiation usually begins with myoblast anchorage to the substrate, cell spreading and proliferation to confluence, ${ }^{7,14}$ we first 


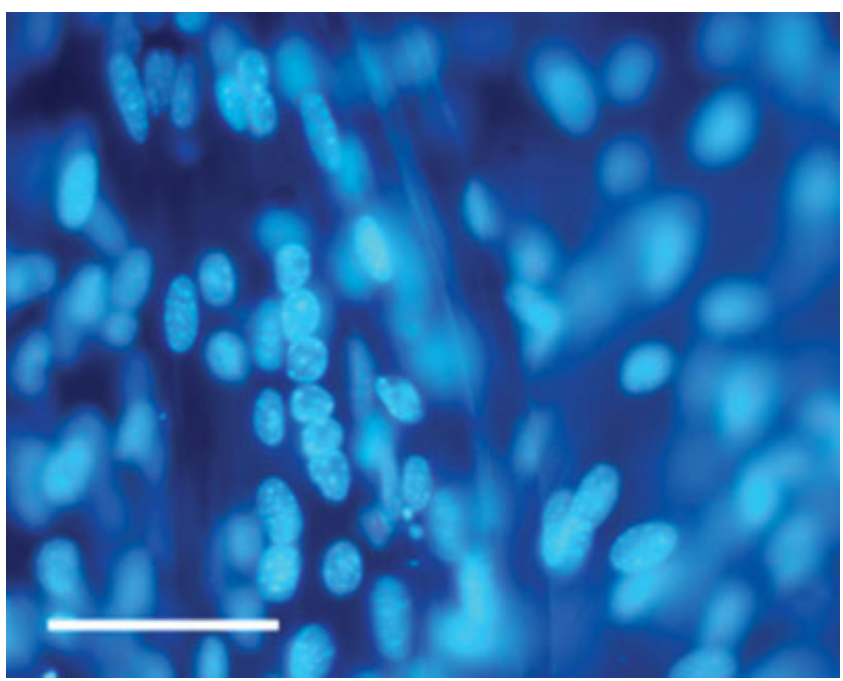

Figure 5. Hoechst staining of $\mathrm{C} 2 \mathrm{C} 12$ nuclei on "O" Degra$\mathrm{Pol}^{\mathbb{R}}$ membranes following 14 days of culture in proliferation medium. Cells are shown to tightly line up in the direction of the scaffold fibers and to lie on different focal plans, indicating that a noncoplanar arrangement of cells occurred. Scale bars $=50 \mu \mathrm{m}$. [Color figure can be viewed in the online issue, which is available at www.interscience. wiley.com.] addressed the issue of cell adhesion and proliferation on newly manufactured DegraPol ${ }^{\circledR}$ scaffolds by means of alamarBlue ${ }^{\mathrm{TM}}$ test. Regardless of the membrane surface morphology (Fig. 1), skeletal myoblasts were shown to be able to proliferate on DegraPol ${ }^{\circledR}$ scaffolds (Fig. 2). Nonetheless, results shown in Figure 2 need to be cautiously considered. Despite the fact that, at each time point, cells on " $\mathrm{O}$ " meshes exhibited significantly higher metabolic activity if compared to cells cultured on "N/O" and " $\mathrm{F}$ " membranes $(p<0.01)$, cell proliferation rates on the three scaffolds were shown to be comparable, the growth curves being approximately parallel to each other. Indeed, the fact that cells on " $\mathrm{O}$ " DegraPol ${ }^{\circledR}$ scaffolds display higher absorbance already at time point DAY 1 suggests that the difference in subsequent values could be traced back to some events that occurred in the first $24 \mathrm{~h}$ after seeding. Ruling out that different initials conditions were introduced by loading uneven amounts of cells on the materials, it is reasonable to conclude that "O" DegraPol ${ }^{\circledR}$ scaffolds show an advantage over "N/O" and " $\mathrm{F}$ " membranes in terms of favoring cell adhesion in the first $24 \mathrm{~h}$ after seeding. As the three scaffolds have identi-
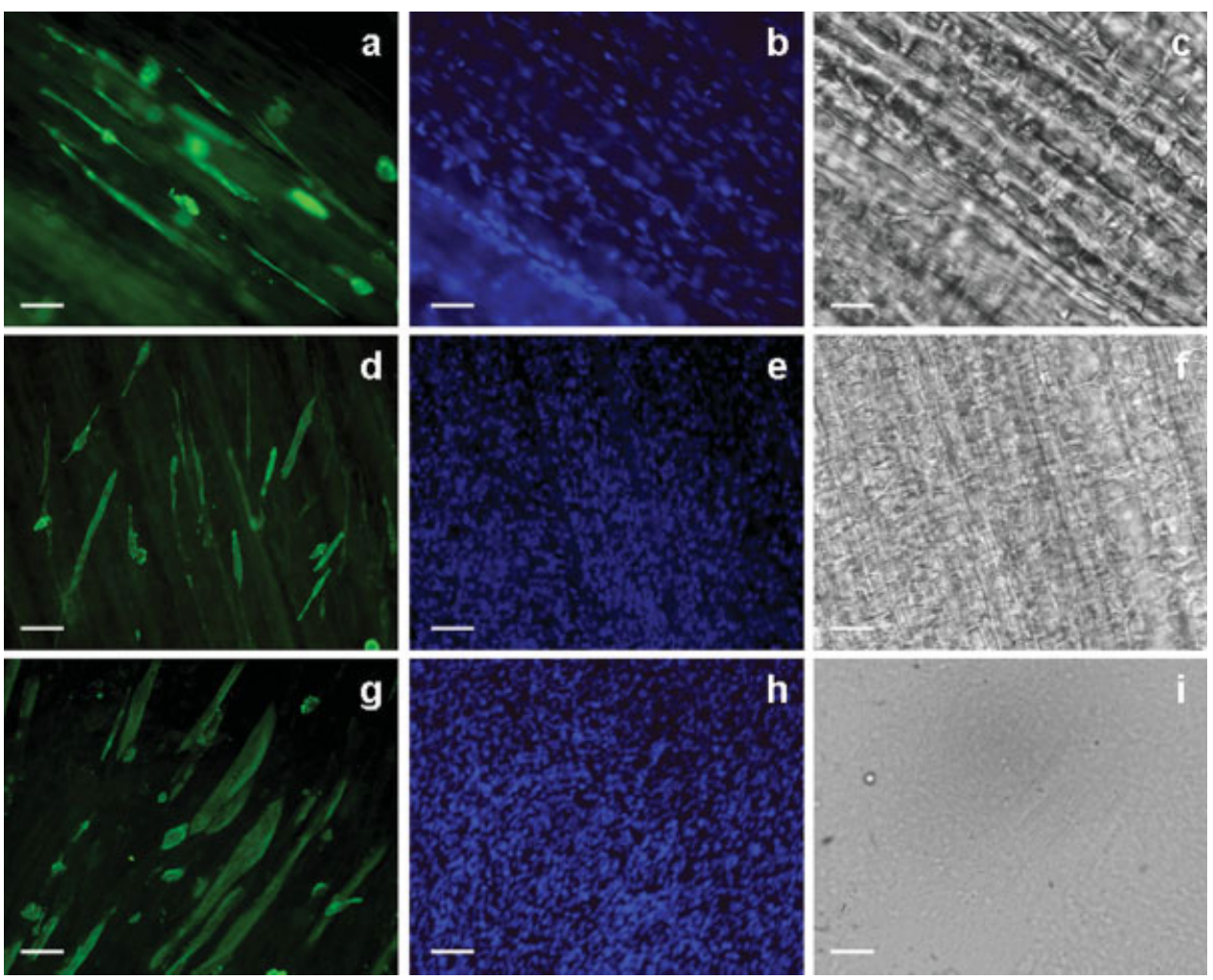

Figure 6. Micrographs of $\mathrm{C} 2 \mathrm{C} 12$ cultured for 14 days on DegraPol ${ }^{\mathbb{R}}$ scaffolds: $(\mathrm{a}-\mathrm{c})$ highly orientated mesh ("O $\left.\mathrm{O}^{\prime}\right)$; $(\mathrm{d}-\mathrm{f})$ nonorientated mesh ("N/O"); (g-i) film ("F"). MHC was marked in green via immunofluorescence, while cell nuclei were stained with Hoechst (in blue). A high degree of orientation of myotubes is observable in the case of "O" DegraPol ${ }^{\mathbb{R}}$, while myotubes grown on "N/O" scaffolds appear randomly distributed; on the nonporous " $\mathrm{F}^{\prime} \mathrm{DegraPol}^{\mathrm{R}}$, similar to what happened on TCPS, myotubes are shown to orient in small colonies, without being able to develop a three-dimensional structure. Scale bars $=100 \mu \mathrm{m}$. [Color figure can be viewed in the online issue, which is available at www.interscience.wiley.com.] 

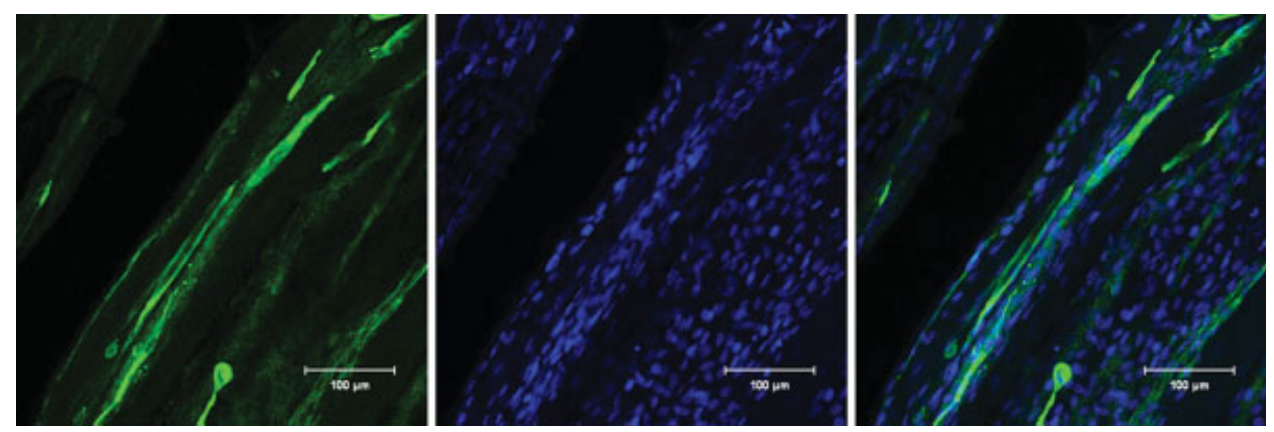

Figure 7. Confocal micrographs of multinucleated myosin expressing myotubes lying about 70 $\mu \mathrm{m}$ below the surface of “O" DegraPol ${ }^{\mathrm{R}}$ scaffolds. Blue staining refers to Hoechst, while green represents the FITC-conjugated secondary antibody for MHC. Myotubes, more than $200 \mu \mathrm{m}$ in length, were cultured for 14 days. [Color figure can be viewed in the online issue, which is available at www.interscience.wiley.com.]

cal chemical composition and electrospinning processing has been previously demonstrated not to introduce cytotoxic contaminants into the membranes, ${ }^{11}$ it is allowed to infer that the fiber arrangement on the surface of " $\mathrm{O}$ " electrospun DegraPol ${ }^{\mathbb{R}}$ membranes, determining the consequent surface pore architecture, provides an optimal topographical cue for skeletal myoblast adhesion and subsequent proliferation.

\section{Cell differentiation}

Referring to cell differentiation, encouraging results were shown first of all by preliminary RTPCR analysis, by means of which we were able to investigate the expression of typical muscle markers (myogenin and MHC) both by $\mathrm{C} 2 \mathrm{C} 12$ and L6 cultured on DegraPol ${ }^{\circledR}$.

Despite the fact that results shown in Figure 4 were derived in the presence of Matrigel ${ }^{\circledR}$ coating on DegraPol ${ }^{\circledR}$ scaffolds, findings of further proliferation and differentiation studies (data not shown) indicate that analogous conclusions could be drawn in the absence of the coating itself. Indeed, the presence of MHC in C2C12 cultured on uncoated Degra$\mathrm{Pol}^{\mathbb{R}}$ was clearly confirmed by subsequent immunofluorescence staining, which showed the development of multinucleated myosin-expressing myotubes on all the scaffolds under investigation (Figs. 6 and 7). Interestingly, while myofibers were randomly distributed on the surface of "N/O" meshes [Fig. 6(d)], on " $\mathrm{O}$ " DegraPol ${ }^{\circledR}$ they clearly aligned in parallel arrays [Fig. 6(a)], coherently with the direction of the underlying scaffold fibers [Fig. 6(c)]. In the case of " $\mathrm{F}$ " DegraPol ${ }^{\circledR}$ [Fig. 6(g)], myoblast behavior revealed similarities to what usually happens on tissue culture polystyrene, since myotubes showed evidences of alignment in short-range distances, but completely lack in overall parallelism. Moreover, though quantitative assessment of cell differentiation was not carried out in this study, $\mathrm{C} 2 \mathrm{C} 12$ fusion index (ratio between the number of nuclei included in myotubes and the total number of nuclei) appeared to be higher on " $\mathrm{O}$ " membranes if compared to "N/O" and " $\mathrm{F}$ " scaffolds (Fig. 6), indicating a greater efficiency of the differentiation process on this type of scaffold. In addition, though our study lacks in an orderly investigation of the behavior of myoblasts within the bulk material, the confocal analysis performed on C2C12-seeded DegraPol $^{\circledR}$ constructs enabled to verify the sporadic presence of multinucleated myotubes lying $70 \mu \mathrm{m}$ below the scaffold surface. Similar to what observed on the scaffold surface, at this depth it was possible to appreciate the guiding effect exerted by the scaffold fibers on the orientation of the developing myotubes (Fig. 7).

In summary, highly orientated ("O $\mathrm{O}$ ") electrospun DegraPol ${ }^{\circledR}$ membranes were shown to enable skeletal myogenesis in vitro aiding in (a) myoblast adhesion, (b) myotube alignment, and (c) noncoplanar arrangement of cells, by providing the necessary directional cues along with architectural and mechanical support. A promising future can be foreshadowed for " $\mathrm{O}$ " DegraPol ${ }^{\mathrm{R}}$ membranes in the field of skeletal muscle tissue engineering, as our results hint at the possibility of (a) accelerating the cell-cell contact formation during cell culture (thus reducing the time to tissue development), (b) generating a well-defined architecture of fully differentiated myofibers organized into parallel contractile units, and (c) arranging the developing tissue in a three-dimensional construct, all of these being key factors in engineering functional skeletal muscle tissue constructs.

In addition, most likely due to their flexibility, ${ }^{7}$ electrospun DegraPol ${ }^{\circledR}$ membranes were shown in this study to allow culture of muscle fibers for extended periods of time (14 days), while myotubes usually tend to detach from rigid substrates 3 to 10 days after development, due to their sarcomeric maturity leading to spontaneous contractile activity. $4,17,18$ Moreover, thanks to the guidance exerted by the scaffold fibers, "O" electrospun DegraPol ${ }^{\circledR}$ membranes were able to prevent myotube branching, thus con- 
tributing to increase the directionality of the resulting construct architecture and allowing for the potential generation of an effective vectorial power.

Along with the above cited aspects, electrospun DegraPol ${ }^{\mathbb{R}}$ membranes combine several other advantages, proposing them as ideal candidate scaffolds for skeletal muscle tissue engineering. Among these, suitable mechanical and degradative properties are worth mentioning, since the material has been previously shown to exhibit linear elastic behavior in the $0-10 \%$ deformation range, deformations at break higher than $200 \%$ and an elastic modulus around $10 \mathrm{MPa}$, while degradation time in buffered aqueous solution was found to be of about 6 months. ${ }^{11}$ Such features are of primary importance in the engineering of soft tissues and in view of future long-term dynamic culture experiments in bioreactors, since they allow to overcome issues related to the relative inflexibility and nondegradability of traditional polymeric substrates. ${ }^{4,9,11}$

In conclusion, our results suggest a huge potential of highly orientated DegraPol ${ }^{\mathbb{R}}$ microfibrous membranes for therapeutic treatment of skeletal muscle injuries, but also for isolation of mechanisms underlying cell-matrix interactions, extending to their role in differentiation. Further efforts are warranted toward increasing the efficiency of differentiation processes on highly orientated meshes, inducing packing of myotubes. In addition, studies are underway to quantify myoblast differentiation potential on the scaffold (via determination of the fusion index and/ or Western Blot analysis of MHC), together with the investigation of different myosin isoforms, determining the type of fibers in culture.

\section{CONCLUSIONS}

In this study, we succeeded in demonstrating that skeletal myogenesis can be obtained, directed, and maintained within the fibers of highly aligned microfibrous DegraPol ${ }^{\circledR}$ scaffolds processed by electrospinning. Our results show that myoblasts can be cultured in a parallel-orientated manner by making use of topographical stimuli from the substrate, enabling the development of a highly-organized architecture, which is essential to obtain forceful and functional skeletal muscle tissue engineering constructs.

We thank Amanda Finan, Carmen Giordano, and Manfred Welti for their helpful assistance in laboratory procedures; Dario Picenoni and Fabio Sangalli for aiding in SEM and confocal microscopy analysis, respectively. Acknowledgements go to Gianfranco Beniamino Fiore, Ivan Martin, and Andrea Banfi for their precious help in the revision of the manuscript.

\section{References}

1. Engler AJ, Sheehan MA, Feng H, Sweeney HL, Discher DE. Cells on gels: Adhesion versus differentiation of skeletal muscle cells, Presented at the 2003 Summer Bioengineering Conference, Key Biscayne, Florida, June 25-29, 2003.

2. Okano T, Satoh S, Oka T, Matsuda T. Tissue engineering of skeletal muscle: highly dense, highly oriented hybrid muscular tissues biomimicking native tissues. ASAIO J 1997;43: M749-M753.

3. Okano T, Matsuda T. Tissue engineered skeletal muscle: preparation of highly dense, highly oriented hybrid muscular tissues. Cell Transplant 1998;7:71-82.

4. Cooper ST, Maxwell AL, Kizana E, Ghoddusi M, Hardeman EC, Alexander IE, Allen DG, North KN. C2C12 co-culture on a fibroblast substratum enables sustained survival of contractile, highly differentiated myotubes with peripheral nuclei and adult fast myosin expression. Cell Motil Cytoskeleton 2004,58:200-211.

5. Xu CY, Inai R, Kotaki M, Ramakrishna S. Aligned biodegradable nanofibrous structure: A potential scaffold for blood vessel engineering. Biomaterials 2004;25:877-886.

6. Dunn GA. Contact guidance of cultured cells: a survey of potentially relevance properties of the substratum. In: Bellairs R, Curtis A, Dunn G, editors. Cell Behavior. Cambridge: Cambridge University Press; 1982. p 247-280.

7. Engler AJ, Griffin MA, Sen S, Bönnemann CG, Sweeney HL, Discher DE. Myotubes differentiate optimally on substrates with tissue-like stiffness: Pathological implications for soft or stiff microenvironments. J Cell Biol 2004;166:877-887.

8. Patz TM, Doraiswamy A, Narayan RJ, Modi R, Chrisey DB. Two-dimensional differential adherence and alignment of C2C12 myoblasts. Mater Sci Eng B 2005;123:242-247.

9. Neumann T, Hauschka SD, Sanders JE. Tissue engineering of skeletal muscle using polymer fiber arrays. Tissue Eng 2003; 9:995-1003.

10. Cronin EM, Thurmond FA, Bassel-Duby R, Williams RS, Wright WE, Nelson KD, Garner HR. Protein-coated poly(Llactic acid) fibers provide a substrate for differentiation of human skeletal muscle cells. J Biomed Mater Res A 2004;69: 373-381.

11. Riboldi SA, Sampaolesi M, Neuenschwander P, Cossu G, Mantero S. Electrospun degradable polyesterurethane membranes: Potential scaffolds for skeletal muscle tissue engineering. Biomaterials 2005;26:4606-4615.

12. Stankus JJ, Guan J, Wagner WR. Fabrication of biodegradable elastomeric scaffolds with sub-micron morphologies. J Biomed Mater Res A 2004;70:603-614.

13. Courtney TD, Sacks MS, Stankus JJ, Guan J, Wagner WR. Analysis and design of novel electrospun PEEU scaffolds for soft tissue engineering, Presented at the 2005 Summer Bioengineering Conference, Vail, Colorado, June 22-26, 2005.

14. Milasincic DJ, Dhawan J, Farmer SR. Anchorage-dependent control of muscle-specific gene expression in C2C12 mouse myoblasts. In Vitro Cell Dev Biol 1996;32:90-99.

15. Azmi S, Ozog A, Taneja R. Sharp-1/DEC2 inhibits skeletal muscle differentiation through repression of myogenic transcription factors. J Biol Chem 2004;279:52643-52652.

16. Bischofs IB, Schwarz US. Cell organization in soft media due to active mechanosensing. PNAS 2003;100:9274-9279.

17. Dennis RG, Kosnik PE, Gilbert ME, Faulkner JA. Excitability and contractility of skeletal muscle engineered from primary cultures and cell lines. Am J Physiol Cell Physiol 2001;280: C288-C295.

18. Huang YC, Dennis RG, Larkin L, Baar K. Rapid formation of functional muscle in vitro using fibrin gels. J Appl Physiol 2005;98:706-713. 